\title{
Monitoring teenage pregnancy in Hull: bespoke local data trump ONS statistics
}

\author{
James Trussell, Kate Guthrie, Kelly Cleland
}

\section{Background}

The Teenage Pregnancy Strategy has set a target of halving the pregnancy rate of women under the age of 18 years and of establishing a firm downward trend in the pregnancy rate of women aged under 16 years. ${ }^{1}$ Progress toward achieving this target is measured both nationally and locally by monitoring teenage pregnancy statistics, produced by the Office for National Statistics (ONS) from induced abortion notifications and birth registrations. Spontaneous and illegal abortions are not included. ONS release conception statistics for under-16 and under-18 age groups. The date of conception is estimated as the date of outcome minus number of days of gestation (Box 1) for abortions and stillbirths, and the date of birth minus 266 days (38 weeks) for live births. A woman's age at conception is calculated as the number of completed years between her date of birth and the date she is estimated to have conceived. The postcode of the woman's address at time of birth or abortion is assumed to be the same as the postcode at the time of conception. Conception statistics are available for England \& Wales, England, Government Office Regions and Local Authorities. ${ }^{2}$

\section{Limitations of ONS methodology}

The ONS methodology can result in incorrect assignment of geographical location or of age at conception and certainly underestimates the number of conceptions, as the reliability of ONS statistics is compromised by the following limitations.

1 Postcode at pregnancy outcome is assumed to be postcode at conception.

2 Gestational age is assumed to be 38 weeks for all live births.

3 Pregnancies ending in a spontaneous abortion are not included. The number of spontaneous abortions can be roughly estimated as $20 \%$ of the number of births plus $10 \%$ of the number of induced abortions, ${ }^{3}$ so the underestimate of conceptions is not trivial.

4 Date of conception for a stillbirth or an induced abortion is estimated as the date at outcome minus gestational age in days. This is actually an estimate of the date of the woman's last menstrual period. The date of conception (fertilisation) would be about 2 weeks later.

Moreover, it is not possible to determine the fraction of

J Fam Plann Reprod Health Care 2008; 34(2): 75-77

Office of Population Research, Princeton University, Princeton, NJ, USA

James Trussell, PhD, Director and Professor of Economics and

Public Affairs (also Visiting Professor, The Hull York Medical

School, Hull, UK)

Sexual and Reproductive Healthcare Partnership, Hull and East Yorkshire, Hull, UK

Kate Guthrie, FRCOG, MFSRH, Consultant Gynaecologist

Office of Population Research, Princeton University, Princeton, NJ, USA

Kelly Cleland, MPA, MPH, Research Specialist

Correspondence to: Professor James Trussell, Office of Population Research, Wallace Hall, Princeton University, Princeton NJ 08544, USA. E-mail: trussell@princeton.edu

\begin{abstract}
Box 1: Definitions of terms used
Gestation is reported in completed weeks and the estimate in days is 7 times reported gestation in weeks. For example, a gestation of 10 weeks and 3 days is reported as 10 weeks.

Therefore estimated gestation in days is on average about $31 / 2$ days too short.

Gravidity is defined as the number of times that a woman has been pregnant and parity is defined as the number of times that she has given birth to a fetus with a gestational age of 24 weeks or more, regardless of whether the child was born alive or was stillborn.
\end{abstract}

conceptions that are first conceptions (or repeat conceptions), data important for strategic planning and evaluation. For registration of births, information on the prior number of births is provided; if stillbirths are included, the result is parity (Box 1). ${ }^{4}$ To determine whether a pregnancy is a first conception, one needs information on the number of times the woman has ever been pregnant (this statistic is gravidity). Information from Abortion Notification Form HSA4 can be used to compute gravidity, but not parity, of women undergoing induced abortions (Box 2). ${ }^{5}$

\section{Availability of ONS statistics}

However, these problems pale in comparison with the delay in availability of the statistics: "ONS usually release conception statistics around 14 months after the period to which they relate. The reason for this time lag is that to be able to record a conception ONS require information on the birth or abortion resulting from that conception. As birth registration can be legally undertaken up to 6 weeks after birth, information on a birth may not be available until 11 months after the date of conception. When all birth and abortion data are available, ONS require 3 months to compile the conception statistics. ONS release annual conception data in February each year (i.e. 2005 data became available in February 2007)." 2

Can one imagine trying to manage the economy with unemployment statistics that are at least 14 months and as much as 25 months old? Here, it seems, the perfect is the enemy of the good.

Box 2: Calculation of gravidity, but not parity, of women undergoing induced abortions using information supplied on the Abortion Notification Form HSA4

Under The Abortion Regulations 1991, as amended, any practitioner who terminates a pregnancy is required to send a notice of, and information about, the induced abortion to the

Chief Medical Officer. Such information and notice are provided on the Abortion Notification Form HSA4.

Instructions on Form HSA4 (erroneously) state: "For parity

[sic], please enter the numbers of any previous pregnancies (resulting in livebirths and stillbirths over 24 weeks;

spontaneous miscarriages and ectopic pregnancies; or legal terminations) in the boxes as appropriate, e.g. ' $01+00+00$ '. If, for example, a woman has had one live birth and one stillbirth, please enter as '02' rather than ' 11 '." What is required here is the number of previous pregnancies, not births, so the word parity is used incorrectly when the word gravidity should be used. A woman with one prior twin birth and no other

pregnancies would be reported as ' $01+00+00$ '. Her parity, however, is clearly 2 . 


\section{Local statistics generated for Hull}

We decided in Hull to produce more timely statistics using locally generated data to inform the local Teenage Pregnancy Strategy. The principal provider unit for Hull is Hull and East Yorkshire Hospitals NHS Trust. Some abortion care is outsourced to the British Pregnancy Advisory Service (bpas). Data are collected differently for obstetric and gynaecology patients in the hospital information system. Women become obstetric patients at their first antenatal visit (antenatal booking visit). Virtually all women undergoing induced abortions are gynaecology patients. In October 2007, we extracted data on births and induced abortions that occurred from 2001 through to September 2007 and data on pregnancies ongoing on 30 September 2007 from the information from the latest antenatal visit, for antenatal bookings that occurred from January through to September 2007. Clearly the data are not perfect for the reasons detailed below.

1 Data on births and induced abortions for Hull women outside the Hull Royal Infirmary are missing. We were able, however, to obtain from bpas data on induced abortions that occurred to women with Hull postcodes.

2 Gestational age and gravidity are not available in electronic form for women undergoing induced abortions in the Hull Royal Infirmary. Therefore we assumed gestational age is 70 days for all. The incidence of repeat pregnancy cannot be estimated.

3 The file of Hull postcodes is current as of August 2007. We assume that these postcodes apply to the period 2001-2006 as well.

4 Gestational age for births is available in weeks and days (e.g. 39 weeks and 4 days). To match the ONS procedure, however, we ignore this information and instead assume that all gestations are exactly 38 weeks.

5 The woman's postcode is updated every time she visits the hospital. Thus, for example, the postcode at the time of a birth in 2003 may be different from the postcode we retrieved in October 2007.

6 A woman with an antenatal booking in 2007 who subsequently had an induced abortion at bpas before October 2007 would be double-counted. So would the same woman if she migrated from being an obstetric patient to a gynecology patient when having a therapeutic abortion in Hull Royal Infirmary. However, this problem appears to be minor since few pregnant teenagers in Hull change their mind about continuing a pregnancy; moreover, the continuing pregnancy will disappear in subsequent quarterly updates; for example, if the antenatal booking were in Q1 2007, that pregnancy ongoing on 30 September 2007 would disappear in the next quarterly update, since antenatal bookings in Q1-Q3 2007 are replaced by bookings in Q2-Q4 2007. A woman with an ongoing pregnancy on 30 September 2007 who later had a miscarriage would be counted as a conception leading to a birth in the current analysis (but this conception would disappear in subsequent quarterly updates when the outcome would be recorded as a miscarriage).

\section{Analysis of the Hull statistics}

Despite these limitations, we were able to produce statistics that we judge to be good enough for monitoring purposes; a month after the data were extracted, these statistics were presented at a meeting of the Hull Teenage Pregnancy Partnership Strategic Group. Conception statistics are certainly complete through the first quarter of 2007 but are not fully complete through the second quarter of 2007, since not all first antenatal bookings and induced abortions would have taken place within the first 3 months of pregnancy. Nevertheless, these second quarter data can be quite useful; while a decline in the second quarter might be due to incomplete data, a finding of no decline would logically be real, since the actual numbers could be only higher. We were disappointed that we could not replicate exactly ONS statistics on births for the period 2001-2005 since we used the same algorithm (our estimate was $1 \%$ too low), but there was no obvious trend in differences for either births or induced abortions (Table 1).

Were we relying on ONS data, our monitoring would by necessity have ceased in the calendar year 2005. By using our locally generated statistics, we were able to conduct a more relevant and timely assessment of teenage pregnancy trends, with statistics that are a year and a half more current than the ONS data. Moreover, we were able to examine data by quarter and by postcode. The value can be seen in Figures 1-3, an illustrative subset of the complete set of figures for all quarters and postcodes. Figures 1 and 2 show for all Hull postcodes and for postcode HU9 no clear trend

Table 1 Comparison of conception statistics generated nationally and locally in Hull for females aged 17 years and younger at conception

\begin{tabular}{|c|c|c|c|c|c|c|c|c|c|}
\hline \multirow[t]{2}{*}{ Source } & \multicolumn{3}{|l|}{2001} & \multicolumn{3}{|l|}{2002} & \multicolumn{3}{|l|}{2003} \\
\hline & $\begin{array}{l}\text { Total } \\
\text { (n) }\end{array}$ & $\begin{array}{l}\text { Leading } \\
\text { to abortion } \\
\text { (n) }\end{array}$ & $\begin{array}{l}\text { Leading } \\
\text { to birth } \\
\text { (n) }\end{array}$ & $\begin{array}{l}\text { Total } \\
\text { (n) }\end{array}$ & $\begin{array}{l}\text { Leading } \\
\text { to abortion } \\
\text { (n) }\end{array}$ & $\begin{array}{l}\text { Leading } \\
\text { to birth } \\
\text { (n) }\end{array}$ & $\begin{array}{l}\text { Total } \\
\text { (n) }\end{array}$ & $\begin{array}{l}\text { Leading } \\
\text { to abortion } \\
\text { (n) }\end{array}$ & $\begin{array}{l}\text { Leading } \\
\text { to birth } \\
\text { (n) }\end{array}$ \\
\hline $\begin{array}{l}\text { National (ONS) } \\
\text { Local (Hull) } \\
\text { Difference } \\
\text { \% Difference }\end{array}$ & $\begin{array}{l}353 \\
350 \\
3 \\
1 \%\end{array}$ & $\begin{array}{r}109 \\
111 \\
-2 \\
-2 \%\end{array}$ & $\begin{array}{r}244 \\
239 \\
5 \\
2 \%\end{array}$ & $\begin{array}{l}339 \\
333 \\
6 \\
2 \%\end{array}$ & $\begin{array}{c}108 \\
111 \\
-3 \\
-3 \%\end{array}$ & $\begin{array}{c}231 \\
222 \\
9 \\
4 \%\end{array}$ & $\begin{array}{l}365 \\
392 \\
-27 \\
-7 \%\end{array}$ & $\begin{array}{l}113 \\
136 \\
-23 \\
-20 \%\end{array}$ & $\begin{array}{r}252 \\
256 \\
-4 \\
-2 \%\end{array}$ \\
\hline \multicolumn{10}{|c|}{ Table 1 (continued) } \\
\hline \multirow[t]{2}{*}{ Source } & \multicolumn{3}{|l|}{2004} & \multicolumn{3}{|l|}{2005} & \multicolumn{3}{|c|}{ 2001-2005 } \\
\hline & $\begin{array}{l}\text { Total } \\
\text { (n) }\end{array}$ & $\begin{array}{l}\text { Leading } \\
\text { to abortion } \\
\text { (n) }\end{array}$ & $\begin{array}{l}\text { Leading } \\
\text { to birth } \\
\text { (n) }\end{array}$ & $\begin{array}{l}\text { Total } \\
\text { (n) }\end{array}$ & $\begin{array}{l}\text { Leading } \\
\text { to abortion } \\
\text { (n) }\end{array}$ & $\begin{array}{l}\text { Leading } \\
\text { to birth } \\
\text { (n) }\end{array}$ & $\begin{array}{l}\text { Total } \\
\text { (n) }\end{array}$ & $\begin{array}{l}\text { Leading } \\
\text { to abortion } \\
\text { (n) }\end{array}$ & $\begin{array}{l}\text { Leading } \\
\text { to birth } \\
\text { (n) }\end{array}$ \\
\hline $\begin{array}{l}\text { National (ONS) } \\
\text { Local (Hull) } \\
\text { Difference } \\
\text { \% Difference }\end{array}$ & $\begin{array}{r}412 \\
408 \\
4 \\
1 \%\end{array}$ & $\begin{array}{c}133 \\
133 \\
0 \\
0 \%\end{array}$ & $\begin{array}{r}279 \\
275 \\
4 \\
1 \%\end{array}$ & $\begin{array}{l}369 \\
381 \\
-12 \\
-3 \%\end{array}$ & $\begin{array}{l}112 \\
127 \\
-15 \\
-13 \%\end{array}$ & $\begin{array}{c}257 \\
254 \\
3 \\
1 \%\end{array}$ & $\begin{array}{l}1838 \\
1864 \\
-26 \\
-1 \%\end{array}$ & $\begin{array}{l}575 \\
618 \\
-43 \\
-7 \%\end{array}$ & $\begin{array}{c}1263 \\
1246 \\
17 \\
1 \%\end{array}$ \\
\hline
\end{tabular}

Source of national estimates: Office for National Statistics (ONS) and Teenage Pregnancy Unit. ${ }^{6}$ 


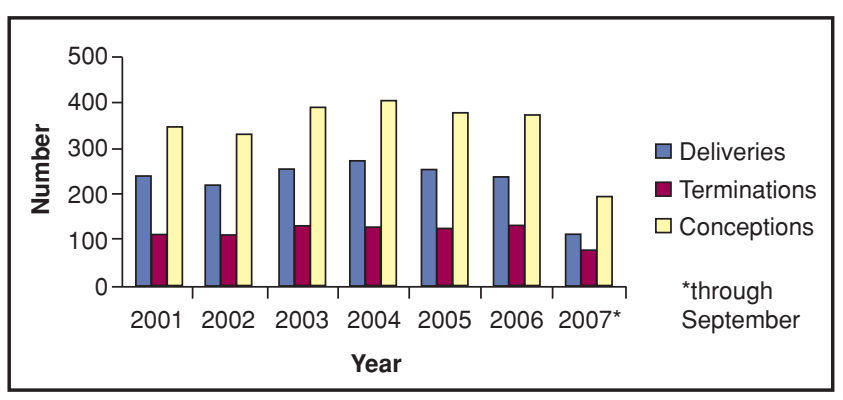

Figure 1 Deliveries, terminations and conceptions by year, all postcodes (Hull statistics)

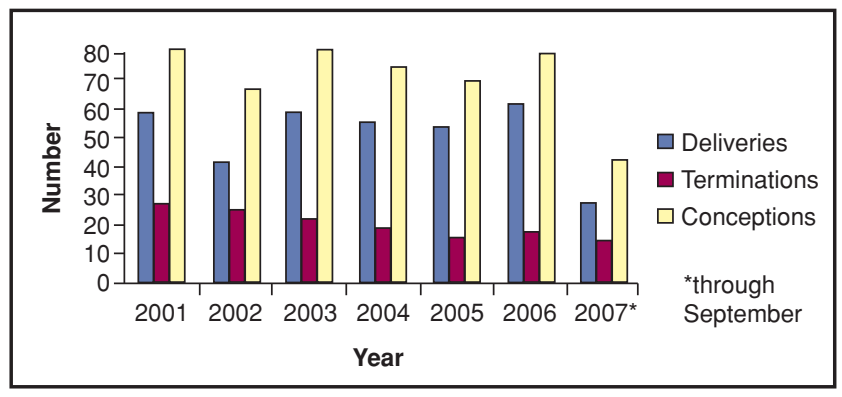

Figure 2 Deliveries, terminations and conceptions by year, postcode HU9 (Hull statistics)

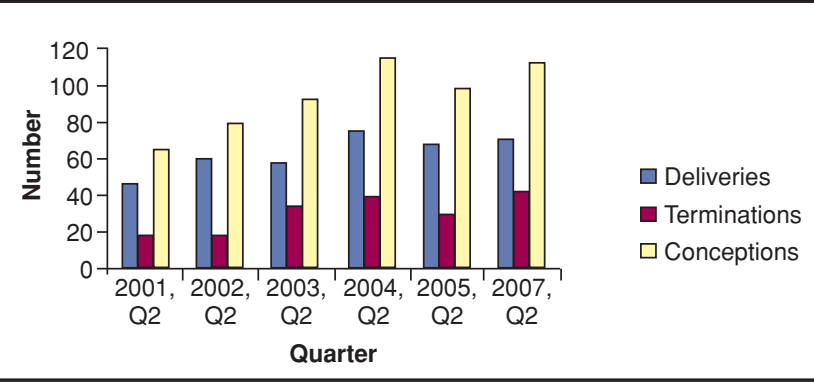

Figure 3 Deliveries, terminations and conceptions for Quarter 2, 2001-2007, all postcodes (Hull statistics)

in conceptions leading to birth, conceptions resulting in induced abortions, or total conceptions to women under the age of 18 years in the period 2001-2006 (the statistics for 2007 are incomplete). Figure 3 shows no downward trend in conceptions leading to birth, conceptions resulting in induced abortions, or total conceptions to women under the age of 18 years in the second quarters of the period 2001-2007; the estimates for 2007 are incomplete so the true numbers can be only higher. Overall, we were able clearly to establish that while our local efforts may have averted a rise in teenage pregnancy, they certainly have not in fact reduced the overall number of pregnancies; nor was progress seen in any postcode. At prior meetings there had been endless speculation about recent trends and complaints about out-of-date data. This meeting produced a moment of sobering clarity.

\section{Lessons learned}

As for lessons we learned that may inform others who want to implement this type of monitoring system, we offer three.

First, having identified the need for gravidity data for induced abortions to look at repeat conceptions and gestation data for induced abortions to estimate better age at conception, we have requested the Commissioners to put this requirement in the Service Level Agreement.

Second, the system would not have been started without the generous support of an outside academic institution. Once started, it is being maintained locally by Hull City Council, and quarterly updates are planned.

Third, the system could have been neither started nor maintained without the generous help of people whose job descriptions did not include the tasks they performed: George Britchford and Sue Kitching (Hull and East Yorkshire Hospital NHS Trust) extracted data on induced abortions and on antenatal bookings and deliveries, respectively, Sue Sarson provided induced abortion data from bpas, and Mandy Porter (Hull Teaching Primary Care Trust) determined if the postcodes in the extracted data were within the Hull boundaries from national lookup files (while all postcodes in Hull begin with the prefix HU, not all postcodes with prefix HU are in Hull). For all involved, this effort has been a labour of love.

\section{Statements on funding and competing interests Funding None identified. \\ Competing interests None identified.}

\section{References}

1 Every Child Matters: Change for Children. About the Teenage Pregnancy Strategy. http://www.everychildmatters.gov.uk/ health/teenagepregnancy/about/ [Accessed 2 February 2008].

2 Definitions of Office for National Statistics (ONS) Conception Statistics. http://www.everychildmatters.gov.uk/ files/Conception $\% 20$ stats - $\% 20$ sources $\% 20$ and $\% 20$ definitions.doc [Accessed 2 February 2008].

3 Leridon H. Human Fertility: The Basic Components. Chicago, IL: University of Chicago Press, 1977; Table 4.20.

4 National Institute for Health and Clinical Excellence (NICE). Routine Antenatal Care: Routine Care for the Healthy Pregnant Woman (Clinical Guideline 6), October 2003. http:// www.nice.org.uk/nicemedia/pdf/CG6_ANC_NICEguideline.pdf [Accessed 2 February 2008].

5 Guidance Note for Completing the Abortion Notification Form HSA4 (in England and Wales). London, UK: Department of Health, September 2006. http://www.dh.gov.uk/prod_consum $\mathrm{dh} /$ idcplg? IdcService $=$ GET_FILE\&dID $=12250 \&$ Rendition $=$ We $\bar{b}$ [Accessed 2 February 2008].

6 Under 18 Conception Data for Top-tier Local Authorities (LAD1), 1998-2005. Source: Office for National Statistics and Teenage Pregnancy Unit. http://www.everychildmatters.gov.uk/ files/04554667B34341D6805E246ED457E906.xls [Accessed 2 February 2008].

\section{READERS' CONTRIBUTIONS INVITED ON 'A BETTER WAY OF WORKING'}

Continuing in this issue (see article on page 128) is the feature entitled 'A Better Way of Working', the purpose of which is to disseminate service delivery suggestions likely to be of interest and relevance to the Journal's readership.

Readers are invited to submit suggestions based on their own personal experience for consideration by the Journal Editor. Contributions should not exceed 250-500 words and should be written in a standardised format responding to the following four questions (or similar): Why was change needed? How did you go about implementing change? What advice would you give to others who might be considering a similar course of action? How did you show that the change had occurred?

All contributions should be submitted via the Journal's online submission system at http://jfprhc.allentrack.net. 